\title{
INDUSTRIAL ENGINEERING CURRICULUM IN INDUSTRY 4.0 IN A SOUTH AFRICAN CONTEXT
}

\author{
S.M. Sackey ${ }^{1} \&$ A. Bester ${ }^{2 *}$
}

\section{ARTICLE INFO}

\begin{tabular}{lr}
$\begin{array}{l}\text { Article details } \\
\text { Submitted by authors }\end{array}$ & 24 Jun 2016 \\
$\begin{array}{l}\text { Accepted for publication } \\
\text { Available online }\end{array}$ & 6 Dec 2016 \\
& \\
\hline $\begin{array}{l}\text { Contact details } \\
\text { * bestera@cput.ac.za }\end{array}$ & \\
\hline $\begin{array}{l}\text { Author affiliations } \\
1 \quad \text { Kwame Nkrumah University of } \\
\text { Science and Technology, Kumasi, } \\
\text { Gahan }\end{array}$ \\
$\begin{array}{l}\text { Department of Industrial } \\
\text { Engineering, Cape Peninsula } \\
\text { University of Technology, Cape }\end{array}$ \\
\begin{tabular}{l} 
Town, South Africa \\
\hline
\end{tabular}
\end{tabular}

DOI

http://dx.doi.org/10.7166/27-4-1579

\section{ABSTRACT}

With its potential to change significantly the knowledge and skillset requirements for industrial engineers (IEs), Industry 4.0 creates a need to reassess the place of IEs to avoid a greater shock than that caused by the information technology identity crisis of the 1990s. This article examines the likely impacts of Industry 4.0 on industrial engineering (IE) and proposes enhancements to IE curricula in South Africa. Research methods include a literature review, a study of IE curricula, and a questionnaire survey of IE programmes. Results indicate that several IE functions might become somewhat transformed, less visible, or downright diminished in Industry 4.0. Emphasis has shifted from traditional IE methods to data-driven functions and cyber-physical systems. The developing mismatch needs correcting by emphasising skills such as 'big data' analytics and novel human-machine interfaces in IE curricula. Only one university in South Africa has made progress towards the adoption of an Industry 4.0 infrastructure. The authors propose a set of curriculum enrichment items as the basis for reform.

\section{OPSOMMING}

Industrie 4.0 het die potensiaal om op 'n beduidende wyse die kennis en vaardigheid vereistes vir bedryfsingenieurs (BI) te verander. Dit skep ook 'n behoefte om die posisie van bedryfsingenieurs te herevalueer, om sodoende die informasie tegnologie identiteitskrisis van die 1990's te vermy. Hierdie artikel ondersoek die waarskynlike impak van Industrie 4.0 op BI met 'n voorgestelde verbeterde kurrikulum in Suid-Afrika. Navorsingsmetodes sluit in literatuuroorsig, BI kurrikulum studie, en 'n vraelys opname van $\mathrm{BI}$ programme. Die resultate dui daarop dat Industrie 4.0 sommige $\mathrm{BI}$ funksies ietwat sal transformeer, minder sigbaar maak, of selfs totaal verminder. Klem verskuif van die tradisionele BI metodes na meer data-gedrewe funksies en kuber-fisiese stelsels. Die ontwikkelingswanaanpassing vererger regstelling deur die beklemtoning van kurrikulum vaardighede soos byvoorbeeld groot datastel analise en nuwe mens-masjien koppelvlakke. Slegs een universiteit toon vordering in die aanvaarding van en implementering van Industrie 4.0 infrastruktuur. Die skrywers stel 'n stel kurrikulum verryking items as basis vir die hervorming voor.

\section{INTRODUCTION}

\subsection{Industrial engineering in Industry 4.0}

It is common knowledge that, in general, the engineering discipline follows technological trends. This is particularly true of industrial engineering (IE), which is defined as "concerned with the design, improvement and installation of integrated systems of people, materials, information, equipment and energy..." [1]. 
The focus of this article is an investigation of the likely impacts on IE education and curriculum of a major current worldwide trend in industry referred to as 'Industry 4.0', and the identification of curriculum content enhancements necessary to accommodate Industry 4.0 concerns. Industry 4.0 marks a major new period in world industry, particularly manufacturing (warranting the label 'fourth industrial revolution' [2, 3]), with great potential to change significantly the way industrial systems work. One area that risks being affected a lot by the impact of change is the profile of the workforce, including industrial engineers (IEs) in particular. In order to avoid a greater shock than the identity crisis of the 1990s, which was caused by the information technology revolution, an emerging challenge is the ability to develop a framework for clarifying the roles of IEs in an Industry 4.0 environment. In addition, it is necessary to identify the potential curriculum reforms that would prepare and give IEs sufficient knowledge so that they can function effectively in Industry 4.0 systems, as well as in traditional organisations.

\subsection{Overall research approach}

In order to conduct this research, the following methods were used: a literature survey to identify the ramifications of Industry 4.0 and its interactions with IE; a curriculum content study of IE programmes; and a questionnaire survey of awareness levels and actions of IE departments in South Africa, as a basis for proposing curriculum enhancements. The justification for this approach is derived from the relative newness of the Industry 4.0 phenomenon.

\section{RESEARCH METHODOLOGY}

\subsection{Aim, scope, and research questions}

The aim of the research was to examine the likely impacts of Industry 4.0 on the IE function, and to determine curricula enhancements necessary to accommodate Industry 4.0 requirements in South African universities. To fulfil this aim, a two-part data collection process was followed: a literature study carried out to review publications relevant to the aim, and a curriculum data collection form relevant for universities. The outcome of the literature search was an initial set of findings that were later combined with data from the other sources to form the final conclusions and basis for determining the requirement for enriching the IE curriculum.

The initial research questions that guided the literature search were:

$>\quad$ What is Industry 4.0?

How do the drivers of Industry 4.0 relate to IE?

$>\quad$ How do the inhibitors of Industry 4.0 relate to IE?

> What changes might occur on the shop floor in Industry 4.0 that will impact the IE function, and in what ways?

$>\quad$ What aspects of IE work will be diminished (and in what form), and what aspects will benefit the most from an Industry 4.0 environment?

$>\quad$ What are possible new areas of knowledge or competence in an Industry 4.0 environment, if any, that IEs have to be exposed to in order to function effectively in their fundamental role as productivity champions?

$>$ How will Industry 4.0 shift the balance of responsibility for actions among universities, regulatory and professional bodies, and the broader education system?

At the very least, the above questions were intended to address the overarching question:

"Are current IE curricula in South African universities adequate to produce engineers able to function effectively in Industry 4.0 systems? And if the answer is 'no', what do IE departments need to do?"

Beyond guiding the literature search, the above question fed into an institution data collection process, with the specific secondary questions having evolved from the outcomes of the former exercise. In order to the chronology, these questions are listed in Section 2.2.3 of this paper, rather than in this section.

\subsection{Search and data gathering strategies}

The following instruments were used to gather data for the study: (i) a literature search on Industry 4.0; (ii) curriculum content search, which was extracted from online websites of relevant IE 
universities in South Africa; and (iii) a questionnaire survey involving issues related to Industry 4.0 and IE in South Africa, which was administered to academic staff from relevant South African IE departments. These instruments are elaborated upon, in turn, in the subsections that follow.

\subsubsection{Literature search on Industry 4.0}

A systematic literature review was conducted using selected research databases. First, the search strategy involved identifying the relevant data sources and key words. These sources included journals, conference proceedings, books, technical reports, and articles from trade journals and company websites. The search was conducted using a range of key words and phrases that might be relevant to Industry 4.0 and its impact on education systems in general, and on IE education in particular. Examples included (but were not limited to) 'Industry 4.0', 'digital manufacturing', 'smart factories', and 'IE curriculum'. The term 'Industry 4.0' was sometimes combined with 'IE' and 'education' in the search. Some literature on Industry 4.0 support infrastructure was also reviewed to broaden the context. Examples of this include literature on 'big data', 'cyber-physical systems', 'Internet of Things', and 'Internet of Services', to illustrate the technological trends involved.

An initial assumption was that journal publications on Industry 4.0 that related directly to IE education would probably be scarce, given that the expression 'Industry 4.0' has been in existence for only a few years. The search field was therefore widened to include a significant number of internet sources.

The results of the literature review were analysed to identify trends and patterns, followed by an interpretation of these to elicit inferences and draw conclusions for curriculum-centred discourse and recommendations.

\subsubsection{Curriculum information from relevant IE institutions}

This was an online process that involved extracting IE curriculum information from the ten universities in South Africa that offer the programme, in order to determine the extent to which Industry 4.0 concepts are already being addressed by curricula, whether explicitly or implicitly.

\subsubsection{Questionnaire survey of awareness and actions among IE departments}

In the next phase of the study, and to get a sense of any trends or plans for the adoption of Industry 4.0 concepts in IE departments, a questionnaire on Industry 4.0 and IE was developed based on findings from the literature. This questionnaire was distributed to the ten universities in South Africa that offer IE, whether traditional, technical, or comprehensive. The questionnaire sought to gather information about the level of Industry 4.0 awareness and any related actions being taken in IE departments. The initial response rate was 50 per cent, but in view of the small size of the total population of ten, this was still felt insufficient, and a decision was thus taken to obtain further data from the remaining institutions by telephone. This yielded some positive results, as it helped the researchers to obtain more data and thus to complete a further four sets of the questionnaire, bringing the total number of respondents to nine.

Nine of these questionnaires were initially done online, whereas in the case of the tenth institution, which was the base for the study, data was collected manually on account of physical proximity. The secondary questions included:

$>$ How is analytics addressed in the IE curriculum?

$>\quad$ Does the IE curriculum cover techniques for human-robot collaboration?

$>\quad$ Does the curriculum introduce students to augmented (virtual) reality systems?

$>$ Beyond simulation, does the IE curriculum accommodate virtual plant models using real-time data?

$>$ How much device data communication/networking knowledge does the IE curriculum offer students?

$>\quad$ In the respondent's view, how should IE departments in universities respond to Industry 4.0 through curriculum content enhancements?

Responses to the above questions were complementarily combined with curriculum information in order to get a clearer picture of the status of Industry 4.0 in IE programmes across South Africa. 


\subsection{Results, analysis, and presentation of initial findings and recommendations}

In the analysis, the focus was on the core functions of IE. As such, no distinction was made in some instances between the various qualifications of IE, such as the National Diploma, the Bachelor of Technology, the Bachelor of Engineering, and the higher degrees; in other places, however, some differentiation has been maintained where necessary, in order to foster the right perspective.

\section{LITERATURE REVIEW}

The literature review formed a major component of the research, as it helped to identify the ramifications and interactions of Industry 4.0 with IE, so that a basis could be constructed for the formulation of suggested curriculum enhancements.

\subsection{Definition and characteristics of Industry $\mathbf{4 . 0}$}

At the outset, it was felt that it was essential to obtain an authoritative definition of Industry 4.0 to support the aim of the research. Industry 4.0 has been defined as:

"a collective term for technologies and concepts of value chain organisation which draws together Cyber-Physical Systems, the Internet of Things, and the Internet of Services" [4, 5].

In Industry 4.0, cyber-physical systems made up of connected systems of software, sensors, machines, workpieces, and communication technologies monitor physical processes, create a virtual copy of the physical world, and make decentralised decisions [2, 6]. This is all done while communicating with one another, with humans, and with centralised controllers in real time as products travel through the production system [2,6]. Over the industrial Internet of Things, these devices interact with decentralised analytics to enable decision-making and real-time responses such as predicting failure, self-configuration, and adapting to changes. Via the Internet of Services, both internal and cross-organisational services are offered and used. Figure 1, by Baur and Wee [7], depicts eight value drivers and 24 dependent industry levers in Industry 4.0. Key functional features of an Industry 4.0 system include: a modular structure for increased flexibility; interoperability, whereby entities communicate seamlessly with each other; virtualisation, with a strong emphasis on simulation and decentralised decision-making; real-time capability for fast response; and a service orientation that gives customers virtual guidance for self-service. Examples of Industry 4.0 are machines that can predict failures and trigger maintenance processes autonomously, or selforganised logistics that react to unexpected changes in production.

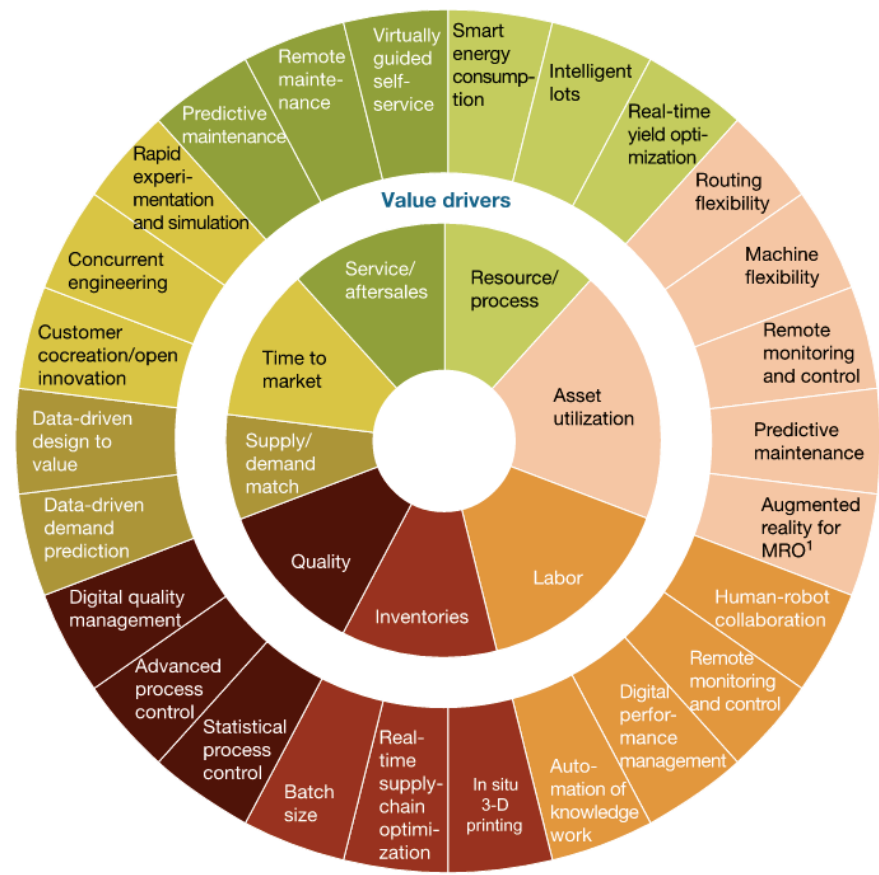

Figure 1: Industry 4.0 value drivers and levers by Baur and Wee [7] 


\subsection{Background and origin of Industry 4.0}

Even though many of the advances in technology that form the foundation for Industry 4.0 have emerged over the last 10 to 15 years [2], Shead [3] reports that the term 'Industry 4.0' was first coined in 2011 by a group of scientists and industry executives who advised the German government on how to develop its technology strategy. (The group completed its report in 2013.) What appears to be giving the phenomenon its current impetus, beyond the industrial influence of Germany, is the maturity and commercial affordability of the underlying technologies [6], and the promise they hold for integrating industrial systems for significant productivity gains.

\subsection{Summary of the effects of Industry 4.0 on industrial systems}

The overall effect of Industry 4.0 on production systems is the customisation of products under conditions of highly-flexible (mass-) production [3, 8], which leads to greater efficiencies and a revolution of traditional production relationships among suppliers, producers, and customers, and between human and machine [2]. According to Germany's National Academy of Science and Engineering [20], these productivity gains can be as high as 30 per cent. And since software now drives more automated machines and manufacturing processes, and robots execute much of it, the required number of workers is reduced [11]. Still, the literature reveals the double-edged nature of Industry 4.0: it creates jobs in some areas and threatens to destroy more in others. Despite this, this subject remains a matter of debate among experts, with some countering the notion that all manufacturing jobs can be automated with the argument that technology will mainly increase productivity through physical and digital assistance systems [11]. These issues will be examined in more detail in later sections of this article.

\subsection{Can Industry 4.0 be taken seriously?}

Information from the literature and other sources seems to suggest that Industry 4.0 will have a strong staying power, and that its promise of significant productivity gains is achievable. In support of this, Baur and Wee [7] maintain that, since Industry 4.0 is a result of a confluence of trends and existing technologies, any notion that the phenomenon is nothing more than a 'flashy catch-phrase' should be dismissed. Shead [3] is even more confident in suggesting a 15- to 20-year time frame before the phenomenon gains full traction and achieves widespread application. Other evidence of the enduring nature of Industry 4.0 is seen in the actions being taken by key industrialised countries such as Germany, the United Kingdom (UK), and China. The German government, for instance, recently committed $€ 200 \mathrm{~m}$ (ZAR $3,232.5 \mathrm{~m}$ ) to help industry associations, research institutes, and companies create an implementation strategy for Industry 4.0 [3]. In the UK, where the core themes of Industry 4.0 have been emerging in research and development facilities, £15m (ZAR 310.5m) has been allocated to research on Industry 4.0 [3]. Juskalian [8] sheds more light on the German story:

"Last year, automotive and industrial exports helped the country post a record trade surplus of 3,200 billion Rands ( $€ 198.9$ billion or $\$ 269$ billion). One reason: automation. Contemporary German auto manufacturing exploits advanced manufacturing technologies to increase productivity and profits. As a result, between 1970 and 2012, the proportion of German employment in manufacturing fell by half, to around 20 per cent (nearly double the U.S. share)".

It would thus seem prudent to reckon with the Industry 4.0 drive while it is still gathering momentum beyond the leading industrial nations.

\subsection{Industrial engineering education and Industry $\mathbf{4 . 0}$}

The literature on Industry 4.0 as it relates directly to IE is only now building up. The closest some researchers have come to making a direct connection is in Shead [3], who - in exploring the implications of Industry 4.0 for education systems in general - referred fleetingly to industrial simulation as a key area where demand for IEs would increase in Industry 4.0. Lorenz and co-workers [11] also observed that in Industry 4.0, manual repetitive tasks and many jobs of a cognitive nature (such as production planning) will be eliminated. In addition, Abele et al. [18] have discussed the effects of Industry 4.0 and noted that "the classic production job profile like industrial engineer increasingly has to dive into the world of information and communication technology to cope with the modelling of complex processes and systems".

While this paucity of relevant literature may be understandable - Industry 4.0 has been around for only a few years - it should not escape notice that most of the gains achievable through Industry 4.0 are being couched in productivity terms - the very raison d'être of IEs. Few would deny, 
therefore, that of all the engineering disciplines, IE stands to be the most adversely affected overall by a full-blown Industry 4.0 environment, unless steps are taken to re-engineer its essence in Industry 4.0. This paper describes research to address this gap of knowledge, with a view to providing a resource that enables academic institutions offering IE to assess their options regarding the Industry 4.0 paradigm, while providing an opportunity to sensitise all the stakeholders, including regulatory bodies, professional associations, and the broader education system.

\subsection{The South African context}

In a recent excellent review of the status and challenges of IE in South Africa, Schutte [9] listed ten industry sectors where IEs in South Africa are employed, and nine IE sub-disciplines where IE-related research is carried out. However, his treatise was totally silent on any effects that the nascent Industry 4.0 could have on IE. For now, it is enough to observe that the four major disruptive information technology trends in Industry 4.0 - big data, advanced analytics, human-machine interfaces, and digital-to-physical transfer - remain potentially applicable to all sectors of industry and not only to manufacturing. For instance, Baur and Wee [7] cite an African gold mine that, by capturing massive data from its sensors, was able through analytics to diagnose unsuspected fluctuations in oxygen levels during leaching (a key process). Fixing this resulted in a 3.7 per cent increase in yield, worth ZAR 287.5 million (US\$ 20 million) annually.

While pointing to ways to accommodate Industry 4.0 in IE curricula, its potential drawbacks in a developing country such as South Africa need also to be acknowledged. Full-blown Industry 4.0 will likely have a significant impact on workers' jobs, as noted, for instance, in the German example above. Other questions relate to whether there will be any scope, willingness, or readiness for skillsupgrading to match the demands of Industry 4.0. To see Industry 4.0 as the cause of general unemployment is to look at the problem precisely the wrong way round. Properly applied, Industry 4.0 can be used to increase productivity, making firms more competitive and thus preserving some jobs. Perhaps it would strengthen the argument to remember that there was a time when competitive struggles for industrial survival took place within a country's borders. Today, however, the barriers have broken down, threatening that local markets are usurped by global firms. Obviously, other industrial countries - notably Germany, Japan, the UK, and the USA - would continue producing as efficiently as possible using these smart, automated systems.

Another relevant issue for South Africa is the interaction of recurriculation with Industry 4.0. Now, since Industry 4.0 is essentially about refining curriculum content, recurriculation will simply determine where this new content goes - if indeed Industry 4.0's principles are recognised.

\section{KEY FINDINGS FROM LITERATURE RELATING TO THE INITIAL RESEARCH QUESTIONS}

The literature review process generated the following findings:

\subsection{How real and enduring is the Industry 4.0 phenomenon?}

Finding 1 (Refer to Sections 3.4 and 3.2)

From all indications, the essence of Industry 4.0 is a real phenomenon that is projected to become the enduring paradigm of the industrial world within the next 15 to 20 years from 2013. The overriding motivation and driving force behind Industry 4.0 is the promise of significant productivity gains and the maturing and affordability of its enabling technologies. Key industrial nations, such as the UK and Industry 4.0's source and champion, Germany, are committing funds to boost its impetus in those countries [7].

\section{Implications for IE}

To avoid missing the fourth industrial revolution, IE stakeholders in South Africa must commit to understanding the implications of Industry 4.0 in order to determine the right balance of responsibility for actions among them.

\subsection{How will changes in the nature of work on the shop floor affect IE functions?}

Finding 2 (Refer to Sections 3.3 and 3.1)

Industry 4.0 will foster significant changes in how industrial workers perform their jobs, and by implication, how IEs function in industrial systems, since their work ultimately depends on shopfloor activities. Entirely new job families will be created, while others will become obsolete. Industry 4.0's advancements will make it possible for an operator to carry out the same types of 
responsibilities at several machines. Consequently, operators will need enhanced capabilities for using digital devices and systems [11].

\section{Implications for IE}

Soft skills will become more important than ever. IEs will be required to provide and optimise stepby-step guidance and instructions for multi-machine operators. IEs will also have to be open to change, possess greater flexibility to adapt to new roles and work environments, and become accustomed to continual interdisciplinary learning.

Finding 3 (Refer to Section 3.3).

Industry 4.0 will dramatically improve the productivity of service technicians in the field by enabling technology-assisted predictive maintenance. Once on-site, a technician will be assisted in making repairs by augmented-reality technology and remote guidance from experts off-site, with automatic documentation of work done in the field [11].

\section{Implications for IE}

IEs will need competencies in deploying and optimising augmented-reality systems, which are touted as able to produce huge productivity gains for original equipment manufacturers and customers alike [11] .

Finding 4 (Refer to Section 3.3)

Some surveys [10] reveal a universal agreement among manufacturers that they will increasingly use robotics and other advanced aids to assist workers, such as relieving line workers from physicallydemanding tasks and improving ergonomics.

\section{Implications for IE}

The significantly improved friendliness of modern robots means that techniques for optimising human-robot collaboration will become important in tackling problems such as physically-demanding and ergonomically-inconvenient jobs.

\subsection{What IE functions will be in strong(est) demand for Industry 4.0?}

Finding 5 (Refer to Sections 3.5, 3.6, 3.1, and Figure 1)

The real-time nature of the inputs and outputs of Industry 4.0 makes real-time simulation and plant virtualisation indispensable in plant operations $[2,3]$.

\section{Implications for IE}

IEs will need IT skills in advanced analytics for simulation that leverages real-time data to produce virtual models of plants for insight and real-time decision-making.

\subsection{What aspects of IE will diminish the most in Industry 4.0?}

Finding 6 (Refer to Figure 1 and Section 3.1)

Using automation to assist workers with manual tasks will diminish several traditional IE functions because these operators will require less machine- and product-specific training.

\section{Implications for IE}

Functions of IE that are likely to diminish the most through the automation of knowledge work in full-blown Industry 4.0 are [11]:

$>$ Production planning.

$>$ Optimisation of manually-performed simple repetitive tasks.

$>$ Traditional manual-intensive statistical process control.

$>$ Manual parts assembly - e.g., on account of 3D printing.

It is remarkable to note that production management is still a high-priority area of IE in South Africa [9]. This runs against the grain of Industry 4.0, where operations research that employs simulation and virtual plant models built on real-time data is the leading IE function.

\subsection{Summary of pointers from the literature review}

From the foregoing sections, and given that data and its automated gathering, processing, and communication is the overarching consideration in Industry 4.0, the authors argue that the following areas need attention in any IE curriculum enhancement initiatives for Industry 4.0: 
Data science and advanced (big data) analytics.

Advanced simulation and virtual plant modelling.

Data communication and networks and system automation.

Novel human-machine interfaces.

Digital-to-physical transfer technologies, such as 3-D printing.

Closed-loop integrated product and process quality control/management systems.

Real-time inventory and logistics optimisation systems.

Teaching and learning demonstration infrastructure.

In the sections that follow, the authors elaborate on each of the above areas in turn, in the light of existing curricula and the general orientation of IE department staff to Industry 4.0.

\section{DISCUSSION: IMPLICATIONS OF INDUSTRY 4.0 FOR INDUSTRIAL ENGINEERING CURRICULA}

\subsection{Advanced (big data) analytics competencies}

Justification: Advanced analytics is a multidimensional discipline that involves the simultaneous application of statistics, computer programming, and operations research to discover and communicate meaningful patterns in data through visualisation for insight. Advanced analytics will therefore equip IEs with the ability comprehensively to evaluate large datasets from many sources, to optimise production quality and support real-time decision-making, such as matching supply to demand. This stands in sharp contrast with the traditional techniques of forecasting, such as Excelbased methods, which are now becoming obsolete. Those performing this role must understand both manufacturing processes and information technology (IT) systems, and possess strong root-causeanalysis skills to identify correlations and draw conclusions [13]. A further skill to be gained is the ability to deploy machine data and functionality to the 'cloud' to facilitate data-driven services for monitoring and controlling production processes. As noted by Burns [14], there is a large scope for training non-data-science professionals such as IEs to perform this role as a cost-cutting measure, despite the value that data scientists can bring to a big data analytics team.

\subsubsection{The traditional universities}

Both the survey and the study of curricula reveal that, in all of the Bachelor of Engineering (BEng) IE programmes, the subject of analytics, at least at the basic levels, is already being taught. For example, 'analytics and synthesis' is one of four major fields offered in Stellenbosch University's BEng IE programme. Curriculum information on operations research at the North West University and the University of Pretoria was sketchy at first, and even more so from the University of the Witwatersrand (Wits). However, data from the survey helped in filling in some of the gaps: at the University of Pretoria, analytics is embedded in other offerings such as operations management and enterprise resource planning systems, simulation modelling, and information systems; whereas at Wits, it is covered under business intelligence systems. Stellenbosch University's information systems syllabus seems open enough to allow for growth.

\subsubsection{Foundations for advanced analytics in the BEng programmes}

Engineering statistics and computer programming seem fairly strong in all four traditional universities, even though full curriculum details could only be obtained from Stellenbosch University. This places them in a strong position to pursue advanced analytics and all its applications in the future, notwithstanding their continued teaching of the traditional (spreadsheet) methods of forecasting. The overarching importance of data in Industry 4.0 would seem to suggest that the approach of Stellenbosch University, in singling out analytics and synthesis for special treatment, holds greater promise for strengthening the foundations for advanced analytics in Industry 4.0.

\subsubsection{The technical universities}

Even though the course 'Information Systems 4' is offered in the BTech programmes, its emphasis in some cases is largely on data modelling for database design. For example, the Cape Peninsula University of Technology (CPUT) focuses on information systems as a tool for student research. Elsewhere, the concentration is on human and management decision support and executive information systems to enable students to communicate effectively with information systems professionals. Further, in seeking to promote systems thinking in simulation, 'Systems Dynamics 4' in the BTech programmes does not make any connection to real-time inputs or analytics. The scope of Information Systems 4 could be expanded to include: data collection systems encompassing sensors, interfaces, hardware, data-to-information transformation processes, and the associated assemblage, organisation and storage of large data sets, and complementary computer networks 
of hardware and software, as well as Internet- and cloud-based information systems. Systems Dynamics 4 could be richer if it were infused with simulation-employing analytics for optimisation processes such as determining optimal product mixes.

Most of the National Diploma (ND) programmes offer nothing explicitly by way of analytics or even information systems. However, the very application of analytics to improve products or production $[12,14]$ requires that at least its fundamental elements be established at that level also, as for the systems dynamics course in the BTech programmes. In this regard, the Tshwane University of Technology (TUT) seems to be moving in the right direction in doing some justice to the subject of analytics in their aptly-named Master's level course 'Data Analysis', as well as in statistics and operations research at the Diploma level. 'Operations Research 3' in the ND programmes, and the simulations it covers, all seem to be traditional in content (Excel-based linear programming), and do not consider large or real-time data sets and analytics. Further, it holds no potential for extension to plant virtualisation - a vital component in Industry 4.0.

\subsubsection{Foundations for analytics in the technical programmes}

Since analytics is founded on statistics, computer programming, and operations research, and since all ND programmes offer the standard courses in operations research and quantitative techniques (statistics), programming skills need to be strengthened to help solidify that foundation. The University of Johannesburg (UJ) offers courses in software design as an elective in separate semesters, while the Nelson Mandela Metropolitan University offers an elective course in computer and programming skills (largely MATLAB-based). This shows that the foundations for advanced analytics are not solid in the ND programmes. Thus it seems that advanced analytics concerns are not being addressed adequately. Further, there is an absence of any real-time elements. Infusing analytics into both the BTech and the ND programmes will help to address this shortcoming, but this will require stronger student foundations in statistics and computer programming. Ensuring such an outcome will require that at least one course in information systems is created for the ND programmes, while the BTech programme's Systems Dynamics 4 course should be upgraded to include more on data science.

\subsection{Advanced simulation and virtual plant modelling capability}

Justification: Simulation built on real-time data to mirror the physical world in a virtual model of the plant is critical for the optimisation of industrial systems [16], and is indispensable in Industry 4.0. This competence will equip IEs to deliver value by applying insights to optimise operations and machine settings in the virtual mode, in advance, to reduce setup times [2].

In the survey, all four traditional universities answered 'no' to the question whether they teach students virtual plant models built on real-time data. This underlines this feature as a quintessential Industry 4.0 characteristic relating specifically to IE, and perhaps reflects the fact that real-time inputs are not easily or meaningfully mimicked in current conventional university lab environments; the implications of this for the 'learning factory' concept are explored in later sections of this paper. However, all four traditional universities seem to offer adequate theoretical preparation in basic simulation, with Stellenbosch University being somewhat more advanced.

As in the traditional universities, none of the technical universities teach virtual plant modelling based on real-time data.

\subsection{Limited computer engineering competencies}

Justification. These competencies will bolster the plant automation credentials of IE students, while positioning them to appreciate better the rationale for problem solution choices in computer engineering. The automation in this module would extend deeper than that currently taught in IE programmes. It is telling that Lorenz et al. [11], in anticipation of the far-reaching changes that Industry 4.0 will require, recommend the acquisition of such skills (building and programming connected systems) as early as in high school.

\subsubsection{The traditional universities}

From the survey, it is evident that very little is taught to students on computer engineering competencies by all the institutions, despite one institution claiming to offer the subject substantially. Even though Stellenbosch University offers mechatronics as an elective in the first year (a year common to all engineering students), prospective IE students are advised not to choose it over another elective course in IE. Mechatronics could represent an efficient way of accommodating mechanical, electronic, computer science, and data communication elements in a 
single course. No such elective in mechatronics is offered by the North West University, the University of Pretoria, or Wits. It is worth noting that Wits already offers mechatronics in the third year of their BEng IE programme.

\subsubsection{The technical universities}

Automation as an explicit course seems to be the exclusive preserve of the ND programmes, where the relevant course is 'Automation 3'. At the Nelson Mandela Metropolitan University (NNMU), the main learning outcome for this course is to design basic automation systems; but this does not indicate how far the course goes in actually delivering this capability. This also applies to the sketchily-described 'Automation 3' course at the Tshwane University of Technology (TUT). Other automation focuses in the ND programmes are on computer numeric control machine programming and robotics (NMMU, CPUT, Durban University of Technology), but their main thrust is in the direction of advanced manufacturing systems rather than automation engineering as such. At UNISA, the subject is presented more as a decision support to enable the choice of manufacturing process. The automation knowledge required in Industry 4.0 must go deeper, to touch automated system elements and their configuration design and control systems, tending to look more like mechatronics. A one-semester course in mechatronics and industrial automation systems could help to address this concern.

\subsection{Novel human-machine interfaces (Technology-assisted work systems)}

\subsubsection{Techniques for human-robot collaboration}

Justification: Advanced, human-friendly robots are expected to be ubiquitous in Industry 4.0 (Section 3.3), where they would work in cooperation with humans without safety fences $[2,10,15]$. 'Robot coordinator' is thus a likely new role in Industry 4.0 [11].

As a probable reflection of the different orientations of the two types of programme, two of the traditional universities' curricula give little attention to this field. In two of the technical universities, however, it reportedly enjoys moderate attention, if only theoretically. Unfortunately, in the other technical universities the answer is a simple 'no'. Although not a formal part of their curriculum, the Tshwane University of Technology claims often to undertake research projects and mount short lectures that seek to provide general education to students and staff on emerging concepts such as collaborative robotics. This seems to be a direct consequence of some staff having a research interest in Industry 4.0.

\subsubsection{Augmented-reality systems and asset use}

Justification: IE functions in this area may include skills for identifying tasks where efficiency and productivity could be enhanced by implementing augmented-reality systems, such as giving remote assistance with basic maintenance tasks or providing customer-specific packaging instructions and after-sales service.

All institutions, both traditional and technical, answered 'no' to the question whether augmentedreality techniques are covered in their curricula; this reflects the relative novelty of the technology. Again, the Tshwane University of Technology claims to offer research projects and lectures that give general education to students and staff about these topics, again reflecting their early interest in Industry 4.0.

\subsubsection{Multi-machine worker assistance systems}

Justification: Important here are skills for designing systems that enable an operator to carry out several operations, including handling work-in-progress and monitoring machine performance and product quality control at several machines. Inventing systems to use automation to assist them with manual tasks becomes paramount. These include formulating standard operating procedures for given tasks that are displayed on screens or augmented-reality glasses [11].

All institutions, both traditional and technical, answered 'no' to this question.

\subsection{Closed-loop integrated product and process quality control/management systems}

Justification: In Industry 4.0, there is a significant automation of knowledge work centering on advanced process control and statistical process control in closed loop systems, which are all managed digitally (Figure 1). Quality control thus becomes data-driven. Such real-time quality control helps companies to resolve any non-conformances quickly. New schemes are needed to accommodate these advanced monitoring regimes and comprehensive to evaluate these data-driven 
quality systems. Such digital solutions allow firms to perform quality parameter checks, store the outcomes, and automatically route any actions when non-compliance occurs.

\subsubsection{The traditional universities}

Stellenbosch University offers both 'Quality Assurance' and 'Quality Control and Management', but other institutions offer either only 'Quality Management' (North West University) or only 'Quality Assurance' (University of Pretoria).

\subsubsection{The technical universities}

In the technical universities, quality assurance is taught in both the ND and the BTech programmes. In the ND programme, the organisational and management aspects of quality and statistical process control, including control charts, are covered; but in the BTech programmes, the scope broadens to include global supply chain quality and process capability. Reference is made to advanced statistical tools and advanced quality techniques and use of computers in quality, but how this is done is not explained. In the BTech programmes, statistical process control and control charts are again taught, but the role of digital quality systems in real-time adaptive quality control loops is missing.

For both types of programme, the ability to visualise large datasets and use algorithms to analyse both real-time and historical data to optimise production quality automatically to support decisionmaking are missing.

\subsection{Logistics optimisation systems}

Justification: Industry 4.0 logistics: using technology such as radio frequency identification (RFID) systems to identify and monitor parts and products (intelligent lots) in the production chain will play a key role in the manufacturing system, and needs to be fully integrated into the curricula of both the BTech and the BEng programmes.

'Industrial Logistics' is offered by the University of Pretoria and 'Logistics Management' is offered by North West University, but Stellenbosch University offers no such course in logistics.

Nothing related to logistics is offered in the ND programmes; and there is no hint of Industry 4.0 elements at all in the logistics engineering/management courses in the BTech curricula.

\subsection{Real-time inventory optimisation systems (Digital-to-physical transfer systems)}

Justification: As an example of digital-to-physical transfer, additive technologies enable complex parts that are difficult to manufacture traditionally to be created in one step, eliminating the need for the assembly and inventories of individual parts (Figure 1). Knowledge and capabilities in 3-D printing systems, their output quality and process capability evaluation, economics of rapid manufacturing, and criteria for process selection will position IEs to make an invaluable contribution in this area.

\subsection{Production technology/Manufacturing systems}

Of the four traditional universities, only Stellenbosch University offers a course in manufacturing systems that address concurrent engineering, flexible manufacturing systems, network automation of manufacturing systems, rapid prototyping, and manufacture.

Even though almost all the ND programmes do mention the subject of computer-integrated manufacturing in the 'Production Technology 4' course, there is a general lack of uniformity in their main concentrations. Whereas some programmes focus on evaluating alternatives and identifying, selecting, planning, and implementing manufacturing technologies (UNISA), the focus of others (UJ, CPUT) is on CAD/CAM process design and concurrent engineering. Only the Durban University of Technology makes reference to automated assembly, inspection, and testing, as well as to automatic identification systems, even if no direct reference to radio frequency identification systems is made. At CPUT, automated material handling and storage is covered, at least in theory.

Topics covered under the 'Production Engineering' (I and II) courses, including forecasting, inventory control, material requirement planning, and quality planning, seem more relevant to production/operations management than to production engineering proper; moreover, they are subjects with diminishing importance in Industry 4.0. 
The interconnectedness of communicating devices in cyber physical systems and the Internet of Things - a common theme in Industry 4.0 systems - seems to be missing in the above courses.

\subsection{Innovative formats for teaching and learning}

As Shuster et al. [17] observe, in Industry 4.0 physical reality meets the virtual world, calling for new formats for teaching and learning. They argue that, since today's students are going to be working in Industry 4.0 contexts, it is important to immerse them in virtual learning environments to gain experience.

The broader literature itself points to an increasing rate of adoption of information and communication technology (ICT) to support engineering education, making teaching and learning more collaborative and virtual. The following combination of teaching/learning demonstration formats is set forth:

$>$ Virtual laboratory;

$>$ A flexible production systems laboratory; and

$>$ Industry 4.0 learning factory.

One traditional IE programme was in the process of creating a physical learning factory. The others do not have any such plans. Van Schalkwyk [19] had earlier made the case for this new didactic approach, articulating its key benefits and characterising it as a supplementary educational method to bridge the gap between abstract lectures in universities and practical experiences required in the work place.

\subsection{How are stakeholders to respond?}

The shifting industrial landscape stemming from Industry 4.0 has significant implications for IE curriculum, its accreditation, and the supporting pre-university education system as a whole. To meet the challenges of Industry 4.0, stakeholder groups will have to prepare for a digital transformation. Universities need to think about how to adapt their curricula and explore the possibilities of more flexible, smarter, modular, and reconfigurable laboratory structures that support and reflect the fluid nature of Industry 4.0.

\subsection{How should the broader education system respond?}

For education systems in general to meet the challenges of Industry 4.0, Lorenz et al. [11] recommend three things: (i) providing broader skill sets; (ii) offering job-specific capabilities; and (iii) closing the IT skills gap. The authors stand in full agreement with this assessment, believing it to be even more relevant in the specific case of IE. In addition, Lorenz et al. [11] even indicate their preference for developing interdisciplinary skills for students as early as the high school level, recommending that traditional study programmes such as mathematics and physics at that level should include additional IT-related and basic engineering coursework with full internships in manufacturing. They maintain that such courses could, for example, combine instruction in building and programming connected systems [11]. They advocate new formats for continuing education, expressing a preference for models that fuse theoretical and practical learning since, in their view; these would be ideally suited for building capabilities related to Industry 4.0 [11]. However, the authors question whether the feasibility of internships at this level would not prove problematic.

\subsection{How should IE curriculum decision-makers in universities respond?}

The responses of academic staff to how Industry 4.0 should be accommodated in IE programmes are varied. Opinions include the following:

1. Fully align with Industry 4.0 (coming from a technical university).

2. Give Industry 4.0 no more than a passing mention in an advanced manufacturing control course at the ND level, and at the BTech level; offer it as an elective linked to material already covered in the ND programme (from a technical university).

3. Industry 4.0 should be introduced at a higher level (from a university of technology).

4. The principles of lean manufacturing should be emphasised (from a technical university).

5. Include Industry 4.0 principles in some of the production and programming modules (from a traditional university). 
The key point here is that Industry 4.0 will create a need for many new cross-functional roles for which workers will need both IT and production knowledge [11]. To foster this, IE departments should increase the number of interdisciplinary courses that integrate IT and IE. They should focus on building specific capabilities required for the new IT tools by adapting their curricula to meet companies' expectations.

\subsection{How should regulatory and accreditation bodies respond?}

To prepare for the changing job requirements of Industry 4.0, regulatory and programme accreditation bodies should work with universities and IE professional bodies to develop a set of specific capabilities for IE, and design ways to assess these capabilities and competencies against set requirements.

\subsection{Summary}

The real-time nature of the inputs and outputs of Industry 4.0 and its automated disposition represent a major difference between Industry 4.0 and traditional industrial systems. Of the areas that need curriculum attention, advanced analytics and system simulation, novel human-machine interfaces, digital-to-physical transfer technologies, and data-to-information conversion processes appear to be the most important. This may explain why operations research built on real-time simulation is turning out to be the most important functional area of IE in Industry 4.0, and why repetitive manual tasks are diminishing. The shifting nature of shop-floor work and the emergence of new roles would impact IE in ways not seen until now. The enduring nature of Industry 4.0 also means that all stakeholders must prepare to adjust to its requirements. This should engage the attention of stakeholders who must first understand precisely how each change has occurred, so that in each case, a meaningful response can be enacted. The discovery that several IE departments in South Africa lack a firm understanding of the nature of a full-blown Industry 4.0 and of its farreaching implications shows that there is a lot of work to be done.

The above efforts should lead to a restructuring of education systems on the principle of broadening interdisciplinary knowledge and skill-sets. This may be the surest way to keep IE still relevant and in charge of its fundamental role as the primary catalyst in productivity improvement in industrial systems. The authors believe that this approach offers a greater potential of effectiveness than leaving the productivity domain to data scientists and other professionals whose basic passion may not be productivity improvement.

\section{CONCLUSION}

This study has sought to investigate the implications of Industry 4.0 for IE curriculum development. Hopefully, it provides a new understanding of IE in digitised, highly-automated industrial systems. The current revolution, involving new and integrated technologies that function on huge data transfers, will call for a re-engineering of IE curricula and the development of cross-functional disciplines to match. It is paramount that all stakeholders in the education system embrace the required reforms, which are expected to be far-reaching. IE departments must come to grips fully with the implications of Industry 4.0 for IE, and be willing to embrace new capabilities derived from data science, computer engineering, and other emerging disciplines. The rationale here is not to turn IEs into professional data scientists or other kinds of professionals, but instead to equip them with sufficient knowledge and skills in those areas to enable them to function meaningfully in their primary role in Industry 4.0. In this regard, IE decision-makers may consider the areas listed in Section 4.5 as they seek to implement the modernisation necessary to meet the demands of Industry 4.0, while still catering to the needs of traditional organisations on the lower rungs of the industrial automation ladder. Given what is at stake, this should trigger national stakeholder debates and other efforts to confront and address the common challenges in a holistic manner.

Future research could focus on evolving a 'model smart production systems model laboratory structure' and Industry 4.0 learning factory in tandem with the above curriculum reforms. Another strand of research could focus on delineating the role and functions of each IE qualification in an Industry 4.0 industrial system. 
The authors gratefully acknowledge the Faculty of Engineering at the Cape Peninsula University of Technology (CPUT), Cape Town, South Africa, for supporting this work.

\section{REFERENCES}

[1] iienet2.org.2015 IIE Industrial Engineering definition. Retrieved from http://www.iienet2.org /details. aspx?id=282. Accessed on 1 September 2015.

[2] Rüßmann, M., Lorenz, M., Gerbert, P., Waldner, M., Justus, J., Engel, P. and Harnisch, M. 2015. Industry 4.0: The future of productivity and growth in manufacturing industries. Retrieved from https://www.bcgperspectives.com/content/articles/engineered_products_project_business_industry_40 future_productivity_growth_manufacturing_industries/. Accessed 1 September 2015.

[3] Shead, S. 2013. Industry 4.0: The next industrial revolution. The Engineer. 11 July. Retrieved from http://www.theengineer.co.uk/manufacturing/automation/industry-40-the-next-industrialrevolution/1016696.article. Accessed on 10 December 2015.

[4] Hermann, M., Pentek, T. and Otto, B. 2015: Design principles for Industrie 4.0 scenarios - A literature review. Technical University, Dortmund. Retrieved from http: / / www.snom.mb.tu-dortmund.de/cms/de/forschung/Arbeitsberichte/Design-Principles-forIndustrie-4_0-Scenarios.pdf. Accessed on 4 January 2016.

[5] Kagermann, H., Wahlster, W. and Helbig, J. 2013. Recommendations for implementing the strategic initiative Industrie 4.0: Final report of the Industrie 4.0 Working Group. Retrieved from http://www.acatech.de/fileadmin/user_upload/Baumstruktur_nach_Website/Acatech/root/de/Material _fuer_Sonderseiten/Industrie_4.0/Final_report_Industrie_4.0_accessible.pdf. Accessed on 6 January 2016.

[6] Khaitan, S. K. and McCalley, J. D. 2015. Design techniques and applications of cyber physical systems: A survey. IEEE Systems Journal, 9(2), pp. 350-365.

[7] Baur, C. \& Wee, D. 2015. Manufacturing's next act. Insights and Publications. Retrieved from http://www.mckinsey.com/business-functions/operations/our-insights/manufacturings-next-act. Accessed on 5 January 2016.

[8] Juskalian, R. 2014. Audi drives innovation on the shop floor. MIT Technology Review. September 16. Retrieved from http://www.i40.de/en/audi-drives-innovation-on-the-shop-floor/. Accessed on 15 December 2016.

[9] Schutte, C.S.L. 2015. The status and challenges of Industrial Engineering in South Africa. Inaugural lecture delivered on 19 October 2015, Department of Industrial Engineering, Stellenbosch University. Sun Media.

[10] Knight, W. 2014. How human-robot teamwork will upend manufacturing, MIT Technology Review. September 16. Retrieved from http://www.i40.de/en/audi-drives-innovation-on-the-shop-floor/. Accessed on 15 December 2016.

[11] Lorenz, M., Rüßmann, M., Strack, R., Lueth, K.L. \& Bolle, M. 2015. Man and machine in Industry 4.0. Bcg Perspectives. Retrieved from https://www.bcgperspectives.com/content/articles/technology-businesstransformation-engineered-products-infrastructure-man-machine-industry-4/. Accessed on 8 December 2015.

[12] Hu, H., Wen, Y., Chua, T. \& Li, X. 2014. Toward scalable systems for big data analytics: A technology tutorial. IEEE Access. 2, pp. 652-687.

[13] Smith, J.A. 2013. Data analytics vs data science: Two separate, but interconnected disciplines. Data Scientist Insights. Retrieved from http://datascientistinsights.com/2013/09/09/data-analytics-vs-data-science-twoseparate-but-interconnected-disciplines/. Accessed on 4 January 2016.

[14] Burns, E. 2016 Analytics team structure can work without data scientists. TechTarget. Retrieved from http://searchbusinessanalytics.techtarget.com/feature/Analytics-team-structure-can-work-without-datascientists. Accessed on 4 January 2016.

[15] KUKA System HRC. 2016 Human-robot collaboration technology. Retrieved from http://www.kukasystems.com/en/technologies/Human_Robot_Collaboration/. Accessed on 4 January 2016.

[16] Popovici, K. \& Mosterman, P.J. 2012. Real-time simulation technologies: Principles, methodologies, and applications. CRC Press.

[17] Schuster, K., Groß, K., Vossen, R., Richert, A. \& Jeschke, S. 2015. Preparing for Industry $4.0-$ Collaborative virtual learning environments in engineering education. The International Conference on $E$ Learning in the Workplace (ICELW). New York, NY, USA. 10-12 June, pp. 1-6.

[18] Abele, E., Metternich, J., Tisch, M., Chryssolouris, G., Sihn, W., ElMaraghy, H., Hummel, V. \& Ranz, F. 2015. Learning factories for research, education, and training. Procedia CIRP, 32, pp. 1-6.

[19] Van Schalkwyk, T.D. 2013. Introduction to learning factory concepts: A Stellenbosch University case study. Conference abstract and presentation for SAllE, Spier, Stellenbosch, 2013.

[20] GTAI German Trade \& Invest 2016. Automation Nation. Retrieved from https: / /industrie4.0.gtai.de/INDUSTRIE40/Navigation/EN/industrie-4-0,t=automationnation, did=1371348. html?view=renderPdf. Access on 4 January 2016. 